\title{
COVID-19 Pandemic and Lockdown: Psychological Distress Impact amongst PCL Nursing Students of Nepalgunj Nursing Campus, Kohalpur, Banke, Nepal
}

\author{
Dhakal $\mathrm{S}^{1}$, Kharel $\mathrm{P}^{1}$
}

\begin{abstract}
Introduction: The uncontrolled spread of COVID-19 worldwide has confined millions of people to their homes. In addition to being a public physical health emergency, COVID-19 (Corona Virus Disease 2019) has significantly resulted in a large number of psychological distress and impacts. The career oriented professional students are away from their academic environment. Aims: This study aims to assess the psychological distress impact of the COVID-19 pandemic among the Proficiency Certificate Level Nursing of Nepalgunj Nursing Campus, Kohalpur, Banke, Nepal. Methods: The online survey with a link directed to students of Proficiency Certificate Level (PCL) Nursing of Nepalgunj Nursing Campus, Kohalpur, Banke, Nepal conducted during lockdown (July $16^{\text {th }}$-July $21^{\text {st }} 2020$ ) which was open for 6 days. Sociodemographic characteristics are the independent variables. Psychological distress was constructed using the Kessler Psychological Distress Scale (K10) Scale as a dependent variables. Data were analyzed using Microsoft Excel. Results: The evidence of the survey showed that in total 80.2, \% (severely distressed - 30.7\%, moderately distressed $-29.7 \%$, mildly distressed-19.8\%) of the Proficiency Certificate Level Nursing students of Nepalgunj Nursing Campus, were having psychological distress during COVID-19 pandemic and lockdown assessed by using K10 scale. Conclusion: The present study showed that Proficiency Certificate Level Nursing students were moderately and severely distressed during lockdown of Covid-19 pandemic.
\end{abstract}

Keywords: Adolescence, COVID-19, Distress, Lockdown pandemic, PCL Nursing students, Psychological

Authors:

1. Mrs. Sanjeeva Dhakal

2. Mrs. Prabha Kharel

Address for Correspondence:

Mrs. Sanjeeva Dhakal

Nepalgunj Medical College, Nursing Program

Kohalpur, Banke

E-mail: sanjeeva.dhakal@gmail.com

\section{INTRODUCTION}

The coronavirus (covid-19) broke out in China, towards the end of 2019 and spread to most parts of the world. ${ }^{1}$ Studies across the world reveals that the stress is commonly present in medical, nursing or technical students. The COVID-19 pandemic has had an important impact on the academic world. It is known that higher studies can influence the mental health of students, and especially those studying health sciences. ${ }^{18}$

The lack of appropriate treatment, vaccination and high rate of deaths resulting top priority for physical protection and coping with the implications to people's mental health is no less important and these may result in long-term negative impacts. ${ }^{1}$ The psychological impact itself and the lockdown is likely to be huge. ${ }^{2}$ The covid-19 pandemic could result in increased psychological distress such as post-traumatic stress, depressive and anxiety disorder as well as grief- related symptoms. ${ }^{3}$

A study from China, in response to the covid-19 outbreak, psychological impact on children and adolescents concluded that when the school and colleges were closed nationwide; prolonged duration of school closure and home confinement might have negative effects on physical and mental health because of being less physically active, irregular sleep patterns, weight gain, frustration and boredom, inadequate information, and family financial loss can have even more problematic and enduring effects on children and adolescents. ${ }^{4}$ In Nepal, studies to document stress among the nursing students or students of technical course before and during COVID-19 pandemic are very less.

\section{METHODS}

This was an online survey based study. Ethical approval was obtained from the institutional review committee of Nepalgunj Medical College and online informed consents were obtained before proceeding with the questions with the participants gave informed consent. The participants here are the PCL Nursing students from first year, second year and third year. The informed consent provided two options of 'Yes" for those who volunteered to participate in the study and "No" for those who did not wish to participate. The respondents were clearly informed about the study's aim and objectives and they were free to withdraw anytime, without giving a reason, and that all the information and options provided would be confidential.

Psychological distress was assessed by using Kessler 
Psychological Distress Scale (K10) Scale. ${ }^{5,6}$ A web based survey was open for 6 days (July $16^{\text {th }}$-July $21^{\text {st }} 2020$ ) which took approximately 15 minutes to complete. In Nepal lockdown started from 24 ${ }^{\text {th }}$ March 2020. To assess psychological distress using K10 scale, questionnaires had been send. A link to the survey was distributed to participants via messenger groups. In this paper, psychological distress is defined as an unpleasant feeling or emotion that affects a human beings general functioning and could include negative feelings of self, others and the environment. Proficiency Certificate Level Nursing students were asked to respond to the Kessler Psychological Distress Scale (K10) Scale Questionnaires. The questionnaires were designed for online completion to expedite data gathering whilst covid-19 pandemic was spreading.

The Kessler Psychological Distress Scale (K10) Scale is a 10item questionnaire intended to yield a global measure of distress based on questions about anxiety and depressive symptoms that a person has experienced in the most recent 4 weeks period. ${ }^{5}$ Those questionnaires has be completed by respondents. It is a measure of psychological distress which participants felt during last 4 weeks period. The numbers attached to the respondents (Students), 10 responses are added up and the total scores is the score on the Kessler psychological distress scale (K10). Scores will range from 10 to $50 .^{6}$

Inclusion criteria: All PCL Students of NGMC-Nursing Campus who approved online informed consent were included.

Exclusion criteria: One male student and student's not approving online informed consent were excluded.

The data collected by the respondent was collected in www. google.docs which was evaluated based on the K10 scale. Data were analyzed using Microsoft Excel.

\section{RESULT}

Questionnaires had been sent 119 female students and one male student was excluded but the final respondents were only 101 because respondents were clearly informed that they can free to withdraw anytime without giving any reason while taking informed consent. All the participants were female only between the age group of minimum 15 to maximum 18 years of age doing proficiency level (PCL) nursing in Nepalgunj Nursing Campus. Psychological distress assessment is done with the help of K10 scale. K10 psychological distress scores ranges from 10-50 with higher scores indicating a higher severity of psychological distress. Total scores splitted into four levels of severity. Raw scores under 20 are likely to be psychologically well, score 20-24 indicates mild psychologically well, score 2429 indicates moderate psychological distress and 30 or more indicates severe psychological distress.

In $\mathrm{K} 10$ scale items, items $1,4,7,8,9,10$ are depression items and items 2,3,5,6 are Anxiety. Patients specific psychological distress also can be assess with items (2 and 3) - Nervous, items (5 and 6) Agitated, items (1and 8) fatigue and (items 4, 7, $9,10)$ as negative affect.
Among $101 \mathrm{PCL}$ nursing students, the prevalence of stress (of all level: severely distressed - 30.7\%, moderately distressed $-29.7 \%$, mildly distressed- $19.8 \%$ ) was $80.2 \%$ and prevalence of severe psychological distress was $30.7 \%$ during lockdown.

\begin{tabular}{|c|c|c|c|c|c|}
\hline \multirow[b]{2}{*}{ Questions } & \multicolumn{5}{|c|}{ Response } \\
\hline & $\begin{array}{l}\text { None } \\
\text { of the } \\
\text { time } \\
\text { (Score } \\
1 \text { ) }\end{array}$ & $\begin{array}{c}\text { A little } \\
\text { of the } \\
\text { time } \\
\text { (Score } \\
2 \text { ) }\end{array}$ & $\begin{array}{c}\text { Some } \\
\text { of the } \\
\text { time } \\
\text { (Score } \\
3 \text { ) }\end{array}$ & $\begin{array}{c}\text { Most } \\
\text { of the } \\
\text { time } \\
\text { (Score } \\
4 \text { ) }\end{array}$ & $\begin{array}{l}\text { All of } \\
\text { the } \\
\text { time } \\
\text { (Score } \\
5 \text { ) }\end{array}$ \\
\hline $\begin{array}{l}\text { 1. In the past } 4 \text { weeks, } \\
\text { about how often did you } \\
\text { feel tired out for no good } \\
\text { reason? }\end{array}$ & 1 & 11 & 59 & 26 & 4 \\
\hline $\begin{array}{l}\text { 2. In the past } 4 \text { weeks, } \\
\text { about how often did you } \\
\text { feel nervous? }\end{array}$ & 8 & 23 & 46 & 24 & 0 \\
\hline $\begin{array}{l}\text { 3. In the past } 4 \text { weeks, } \\
\text { about how often did } \\
\text { you feel so nervous that } \\
\text { nothing could calm you } \\
\text { down? }\end{array}$ & 20 & 33 & 38 & 10 & 0 \\
\hline $\begin{array}{l}\text { 4. In the past } 4 \text { weeks, } \\
\text { about how often did you } \\
\text { feel hopeless? }\end{array}$ & 25 & 24 & 35 & 16 & 1 \\
\hline $\begin{array}{l}\text { 5. In the past } 4 \text { weeks, } \\
\text { about how often did you } \\
\text { feel restless or fidgety? }\end{array}$ & 17 & 34 & 32 & 16 & 2 \\
\hline $\begin{array}{l}\text { 6. In the past } 4 \text { weeks, } \\
\text { about how often did you } \\
\text { feel so restless you could } \\
\text { not sit still? }\end{array}$ & 28 & 30 & 28 & 14 & 1 \\
\hline $\begin{array}{l}\text { 7. In the past } 4 \text { weeks, } \\
\text { about how often did you } \\
\text { feel depressed? }\end{array}$ & 31 & 28 & 33 & 9 & 0 \\
\hline $\begin{array}{l}\text { 8. In the past } 4 \text { weeks, } \\
\text { about how often did you } \\
\text { feel that everything was } \\
\text { an effort? }\end{array}$ & 13 & 21 & 36 & 24 & 7 \\
\hline $\begin{array}{l}\text { 9. In the past } 4 \text { weeks, } \\
\text { about how often did you } \\
\text { feel so sad that nothing } \\
\text { could cheer you up? }\end{array}$ & 22 & 26 & 37 & 15 & 1 \\
\hline $\begin{array}{l}\text { 10. In the past } 4 \text { weeks, } \\
\text { about how often did you } \\
\text { feel worthless? }\end{array}$ & 26 & 27 & 32 & 13 & 3 \\
\hline
\end{tabular}

Table I: Students' responses on The Kessler Psychological Distress Scale (K10)

\begin{tabular}{|lccc|}
\hline K10 Score & $\begin{array}{c}\text { Level of psychological } \\
\text { distress }\end{array}$ & No. of students & Prevalence \\
\hline under 20 & Low & 20 & $19.8 \%$ \\
\hline $20-24$ & Mild & 20 & $19.8 \%$ \\
\hline $25-29$ & Moderate & 30 & $29.7 \%$ \\
\hline 30 and over & Severe & 31 & $30.7 \%$ \\
\hline Total & - & 101 & $100 \%$ \\
\hline
\end{tabular}

Table II: Prevalence of severities of psychological distress according to K10 score 


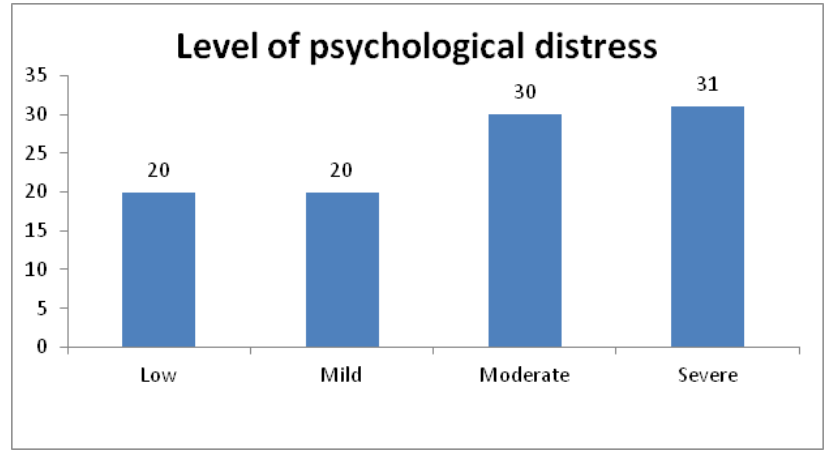

Figure 1: Distribution of Level of psychological Distress and student distribution

\section{DISCUSSION}

The PCL Nursing students get admission after SLC/SEE. Students have to work hard and read regularly their vast courses so that they acquire proper nursing skills and also gain huge amount of theoretical and practical knowledge, which inevitably puts them under great deal of psychological distress. Studies related with the psychological distress related with the covid-19 pandemic associating with nursing students are very limited entirely to collect supportive references. In this study, we therefore sought to assess whether the current pandemic has affected the mental well-being nursing students.

The present scenario created everybody to be confined and locked at their home in the entire world due to Covid-19 pandemic. Students who are under vocational and technical education are continuing with virtual learning but they are distressed psychologically regarding practical knowledge, competent skills and their investments. The corona virus disease 2019 (COVID-19) is profoundly affecting life around the globe; isolation, contact restrictions and economic shutdown impose a complete change to the psychosocial environment. ${ }^{9}$

In our study, 101 students were included. 20 students were psychologically having no distress. Similarly, 20 students were having mild psychological distress. Out of 101, 30 students were moderately and 31 students were having severe level of psychological distress during COVID-19 Pandemic and Lockdown resulting from confining at home and away from college and clinical exposure. The level of psychological distress in total in this study was found to be $80.2 \%$. This level of stress was very close to the level of stress found in the study conducted in medical schools of Saudi Arabia $(63.8 \%)^{12}$ and in Thailand $(61.4 \%)^{13}$ but higher than a study in Egypt $(43.7 \%)^{14}$ or a Malaysian study $(41.9 \%)^{15}$ and a British study $(31.2 \%)^{16}$. This could be either due to the different instruments used in other studies or it could be a real difference of psychological distress created with Covid-19 pandemic and lockdown and being away from the academic environment and academic burden than that ofstudies done before pandemic. Our study is also supported by a study conducted in Nepal to assess stress among medical undergraduate students in NMCTH by
Singh S et al (2017) before Covid-19 by concluding that total prevalence of stress was $62.66 \%$ and the prevalence of severe stress was $21.33 \%$. $^{17}$

A recent study done by $\mathrm{Li} S$ et al (2020)to explore the impacts of COVID-19 on peoples mental health showed that negative emotions (e.g. anxiety, depression and indignation) and sensitivity to social risks increased, while the scores of positive emotions(e.g. oxford happiness) and life satisfaction decreased. ${ }^{7}$ These studies support the present studies. The Kessler 10 Psychological Distress Scale (K10) is a brief dimensional scale designed to measure and monitor trends of psychological distress. ${ }^{10}$

Furthermore, a survey conducted to the general public in china to understand their level of psychological impact, anxiety, depression and stress during the initial stage of the COVID 19 outbreak. It concluded that $53.8 \%$ of respondents rated the psychological impact of the outbreak as moderate or severe; $16.5 \%$ reported moderate to severe depressive symptoms, $28.8 \%$ reported moderate to severe anxiety symptoms; and $8.1 \%$ reported moderated to severe stress levels ${ }^{8}$ supporting our study where $29.7 \%$ students were moderately stressed and $30.7 \%$ were severely stressed. Fegert JM et al in his study observed that child and adolescent psychiatrist ensure continuity of care during all phases of the pandemic; COVID-19 associated mental health risk will disproportionately hit children and adolescents who are already disadvantaged and marginalized. ${ }^{8}$

Rehman A.R. (2020) conducted cross-sectional online survey among residents in Australia, including patients, frontline health and other essential service workers, and community members to assess factors associated with psychological distress, fear and coping strategies during the COVID-19 pandemic were comorbidities such as pre-existing mental health conditions, employment status, alcohol drinking, providing care to known or suspected cases, being female. ${ }^{11}$

\section{LIMITATIONS}

The limitation of study is only PCL Nursing students of Nepalgunj Nursing Campus has included as the source of data collection which do not represent the data of other colleges of nursing or other courses of Banke, Nepal.

\section{CONCLUSION}

The result showed high levels of presence of psychological distress among the PCL Nursing Students Hence, they are being supported by teachers via online classes and student counselling committee of the Nursing Campus kept supporting psychological health which should be further enhanced. Those students who are already in "severe" category of psychological distress level can be advised and supported by teachers by focusing their theoretical study, giving assignments, presentations virtually. So that students and teachers keep interacting, remain engaged in the curricular creativity, activity to keep themselves busy with their nursing study. This study shows that the mental health of students is a significant factor 
and one that must be taken into consideration when training nursing students. There is a need to promote healthy habits and provide appropriate coping strategies. It is also important to train and prepare students for pandemic situations as these can have an important impact on the mental health of both the members of the public who will be treated by these future nursing professionals and the students themselves.

\section{REFERENCES}

1. Shelef L, Zalsman G, the psychological impact of COVID-19 on the mental health-Literature review; International J. Environment research Public Health;2020; 159(5):320-325

2. Chakraorty $\mathrm{K}$,Chatterjee $\mathrm{M}$, Psychological impact of COVID-19 pandemic on general population in West Bengal: A cross-sectional study. Indian J Psychiatry. 2020;62(3):266272

3. Guessoum S.B., Lachal J., Radjack R, Carretier E, Minassian S, Benoit L, Moro MR Adolescent psychiatrict disorders during the COVID 19 pandemic and lockdown 2020;291:113264. doi: $10.1016 /$ j.psycheres.2020.113264

4. Wang G., Zhang Y., Zhao J., Zhang J., Jiang F; Mitigate the effects of home confinement on children during COVID-19 outbreak. March 4, 2020;doi: https;//doi.org/10.1016/ S0140-6736(20)30547-X vol. 395, issue;10228,945-947

5. Kesslers R.C., Andrews G., Colpe et al. Short screening scales to monitor population prevalences and trends in non-specific psychological distress. Psychological Medicine 2002;32:959-956.

6. Andrews G., Slade T. Interpreting scores on the kesslers psychological distress scale (K10). Australian and New Zealand Journal of Public Health 2001;25:494-497.

7. Li Sijia, Wang Y., Xue J., Zhoa N, Zhu T;THE IMPACT OF covid-19 Epidemic Declaration on psychological consequences: A study on active Weibo Users 2020;17(6):2032; doi: 10.3390/ ijerph 17062032

8. Wang C, Pan R, Wan X,Tan Y, Xu L, HoCS, Ho RC;Immediate psychological responses and associated factors during the initial stage of the 2019 coronavirus disease (COVID-19) epidemic among the general population in china; International Journal environmental research public health 2020;17(5):1729. Doi;10.3390/ijerph17051729

9. Fegert JM, Vitiello B, Plener PL, Clemens V; challenges and burden of the coronavirus 2019 (COVID-19) pandemic for child and adolescent mental health: a narrative review to highlight clinical and research needsin the acute phase and the long return to normality. ;child adolescence psychiatry mental health2020 may 12;14;20, doi:10.1186/s13034-02000329-3

10. Sunderland M, Mahoney A, Andrew G, Investigating the factor structure of the Kessler psychological Distress Scale in Community and clinical samples of the Australian population; Journal of psychopathology and Behavioral Assessment 2012;34:253-259 et. Al. Factors associated with psychological distress, fear and coping strategies during the COVID-19 pandemic in Australia; Globalization and Health 2020;16:95; https;//doi. org/10.1186/s12992-020-00624-w

12. Abdulghani HM, Alkanhal AA, Mahmoud ES, Ponnamperuma GG, Alfaris EA. Stress and its effects on medical students: a cross-sectional study at a college of medicine in Saudi Arabia.J Health Popul Nurt 2011;29(5);516-522

13. Saipanish R. Stress among medical students in a Thai medical school. Med Teach. 2003;25:502-6

14. El-Gilany AH, Amr M, Hammad S. Perceived stress among male medical students in Egypt and Saudi Arabia: effect of sociodemographic factors. Ann Saudi Med. 2008;28:442-8

15. Sherina MS, Rampal L, Kaneson N. Psychological stress among undergraduate medical students. Med J Malaysia. 2004;59:207-11.

16. Firth J. Levels and sources in medical students. BMJ. 1986 May 3;292:1177-80. doi: 10.1136/bmj.292.6529.1177.

17. Singh S, Katuwal B, Pant PP, Assessment of stress among medical undergraduate students of Nepal Medical College and Teaching Hospital (NMCTH); International Journal of science and healthcare Research 2017;(3):2455-7587;www. gkpublication.in/ijshr.html

18. Villarroya SR, Ortega L, Lavedan A, Masot O, Marti mdb, Ferrando DB, Pumarola CF, Botigue T; The influence of COVID-19 on the mental health of final-year nursing students: comparing the situation before and during the pandemic 2021;30:(3); 694-702; https://doi.org/10.1111/ inm.12827

11. A. R. Muhammad, N Hoque, M. A. Sheikh, S. Masudus 